\title{
Using Modified Nadler-Tushman Model in GAP Analysis of Educational Process of EFMNS Certified Engineer
}

\author{
Srđan FILIPOVIĆ, Miloš VASIĆ, Slaven TICA, Emil VEG, Goran ŠINIKOVIĆ
}

\begin{abstract}
Main task of this paper was to design a model which would find incongruence in educational process of capable EFMNS certified engineer. Through designed model, scoreboard matrix tables of incongruence of elements were defined. Also, the model represents contenting elements by value of incongruence and impact. Flexible model was observed in variation of changed congruence of specific element and gap analysis of element itself. Educational process was analysed as a system with several levels of output with main researched output in the lowest level-maintenance engineer able to achieve EFMNS certificate. GAP analysis was set as the method suitable for comparing different approaches, styles and set of educational courses provided in the various educational processes. As a base of the model, Nadler Tushman Congruence model was used and modified for better serving the practice. Base model was analysed in order to best use pros and to avoid main cons of the model. Main goal of the paper was to set appropriate model for comparing different elements of the educational process in order to discover their influence and incongruence with the process. The model designed in this paper provides a strong basis in the future gap analysis of educational process and elements of system. Also, the discovered model could be used in analysis of various processes under stated requirements. As a result of this research and analysis, lists of particular educational courses were defined, both for BSc and MSc levels of studying, which can be used both as a standalone or addition to existing educational program. Analysis of defined lists and their impacts on other elements of educational process itself provided several major conclusions which provide constant development of educational process.
\end{abstract}

Keywords: educational programs; EFMNS; engineering; GAP analysis; maintenance; Nadler-Tushman model

\section{INTRODUCTION}

Maintenance, as one of the major engineering disciplines, needs to be conducted in the way that suits purpose, resources and efficiency of the mechanical system which is maintained. Only managed maintenance can provide these qualities and there are numerous examples [1-5].

Maintenance management takes a vast quantity of engineers occupation and professional engagement.

One who manages maintenance has to be educated and trained to use sublimated wide empiria of design and production of the maintained system. On the other hand, maintenance empiria of system itself, skills and knowledge in micro and macro technology of maintenance methodologies and techniques are the least qualities of maintenance engineer. Having all of this is not simple to achieve.

Union of engineers around the globe made rules and waypoints as well as regulations and certifications which differentiate levels of engineering professionals. European Federation of Maintenance National Societies (EFMNS) is one of a few world's best in gathering maintenance professionals [6].

Therefore, if we accept EFMNS recommendations, as a desired basis for maintenance engineer, we have to adopt a list of required knowledge and skills needed for education of maintenance engineer [7].

\subsection{EFMNS Certification}

Certification of EFMNS professionals is established and conducted by EFMNS Certification committee and it is important for an individual as well as for a company employing EFMNS certified maintenance manager sharing values and using strategic drivers through vision and mission of the EFMNS certification committee [8].

Process of EFMNS certification is based upon a unique exam based on the European standard EN 15628-
Qualification of maintenance personnel and the EFNMS' Specification for requirements [9].

Author's research in the field of maintenance standards [10] and related topics reveal the fact that there are numerous standards dealing with this and similar topics, all of which combined with EFMNS certification minimal requirements [11] define minimal basis of engineering knowledge and skills.

As a result of certification, a list of certified professionals is published, i.e. year 2006 [12].

\subsection{Educational Processes of Maintenance Engineers in Europe}

If we make a review of educational processes of maintenance engineers in Europe, we can find a variety of educational programs providing knowledge in different levels of taxonometry of maintenance related topics and courses.

According to the research of the author [13], there are no certified programs of education for EFMNS certified engineer, at the moment of research, but there are research and scientific papers on education of engineers specified for area of sustainable development like [14] and there are listed requirements of desired knowledge and expertise [7, $11]$.

Also, there are models of master's degree thesis developed in order to achieve ability of EFMNS certification in expertise in maintenance management engineering within master's degree [13].

\subsection{Main Goal of Research}

Main purpose of this research (paper) was to establish a model of educational process which can be analysed from several points of view, dealing with all significant factors and elements of the educational process itself. All stated for educational process with minimum criteria of knowledge and expertise of maintenance engineer, capable 
of managing maintenance of technical system according to EFMNS certification standards.

Since there are established minimal requirements of knowledge [11] and there are numerous educational programs, comparing them, in the real environment of educational process of an engineer and finding the model of educational process able to produce EFMNS capable engineer, was the challenge.

As defined by EFMNS recommendations [7] and desirability of master degree education of EFMNS certified maintenance manager, establishing adequate model of educational process was discussed in the matter of bachelor and master degree education, due to the fact that one comes out of the other and the fact that requirements [11] consist of broad spectrum of academic knowledge.

Expected results of this research were to build EFMNS certified program of education, find its impact on the educational process and provide us with related conclusions that arise from it.

\section{ADOPTING SUITABLE ANALYSIS METHOD}

As Requirements and Rules to achieve an EFMNS Certificate as European Expert in Maintenance Management [11] defines, there are four areas of theoretical knowledge required:

I. Management and organization,

II. Reliability performance of production plants,

III. Maintenance information systems, and

IV. Maintenance methods and techniques.

On the other side, Educational process of an engineerstudent in Europe is defined by studying the process based on study programs of one Faculty or University, all of them providing several areas of theoretical knowledge, respectively. Programs are based on international standards of education declared in Bologna Declaration [15] and commonly accredited by national accreditation corps.

In conducting analysis which results in setting desired performance of educational process and programs as well, author has chosen to use GAP analysis, as GAP analysis is a commonly used method in management that uses comparing actual performance with potential or desired performance of one system.

Comparing educational process of maintenance engineer through theory of systems with something that has inputs and outputs we certainly find that the system is educational process itself with inputs and outputs defined.

In this research, GAP analysis was used in comparing inputs of concrete educational process with maintenance engineer as output of a system. Also, the instrument that was used in forming a model was one that set principles in fulfilling the gap between required knowledge and educational programs, as actual and desired performance.

As research shows [16] it is common for mechanical engineers as it is for all other fields of educational degree to use simple cost efficient methods in their evaluations and making decisions on investment.

Furthermore, according to [17] judgmental selection of forecasting model is on par, if not better than algorithmic model.

All of the stated, lead to use one of the basic techniques-benchmarking educational system as business system through gap analysis.
In choosing between several GAP analysis models (McKinsey 7S Framework, SWOT analysis and NadlerTushman model) [18], a particular model is one that depends on a specific set of target objectives, process environment and inputs and outputs.

In the last mentioned method, it is clear that outputs exist at the individual, group and organisational levels and that environment has strong influence on process itself and input and outputs of the system.

This makes this method suitable as a base model for using in our case, especially as it identifies relations between key outputs on three levels:

- level one-engineer with ability for EFMNS certification,

- level two-organizations providing EFMNS certification and

- level three-influence on the society (parliament, ministries.).

It can also provide us information on how the various outputs affect each other, and finally what problems/synergies we can see are created by conflict/coordination of outputs, but that was not the main topic of research.

Likewise, environment of process itself and how it affects the system, including all elements of the system and environment itself can be discussed through this method.

First step in analysis was modifying suitable method in order to design a method that approximates educational process as a system.

\subsection{Modifying the Nadler-Tushman Model}

There are several modifications of Nadler-Tushman Congruence model. All of them present GAP analysis model tailored for specific purpose in management and economics $[18,19]$.

According to Margaret Rouse [18] Nadler-Tushman model puts a spotlight on how inadequate inputs and transformation functions that fail to work together cohesively can lead to gaps, as well as how gaps in the outputs can point to problems in the inputs and transformation functions.

Focusing attention on gaps in outputs which points to the problems in inputs and transformational process and taking in consideration statements of Chirantan Basu [19] on how congruence model views organizations as interacting components that exist in relative harmony or fit with one another specially when observing pros and cons of the model, a new Modified Nadler-Tushman model can be designed.

New model SF13 compares business process and educational process using all pros and eliminating cons of the basic model.

Modified Nadler-Tushman provides a framework for analysing complex educational problems. Also, it takes in consideration social components (people and informal structures) and technical components (tasks and formal structures) that must fit as part of the congruence model [19].

As original model, modified model SF13 provides thinking through organizational problems, not a rigid template for classifying observations. As original model the new modified model provides ability to qualify the 
impact of change in management on organizational interactions and performance.

Challenge in modifying Nadler-Tushman model was to eliminate or use cons of the original model to obtain functionality as well as proper aligning of elements and their qualities and interactions. Opposite to original model, modified model SF13 provides structured template, while giving managers flexibility that does not limit their ability in using proven solutions to educational process problems. Modified model SF13 lacks limiting the effectiveness because educational process has to adapt to continuous changing.

Modifying was realized in three steps: choosing suitable Nadler-Tushman model, identifying processes and resources as well as class of resources and inputs/outputs and designing the model with all representative elements and interactions.

\subsection{Transformation using class of resources circuiting the system}

Requirements for benchmarking were:

I. defining analogy of process with profit making process as 'profit means efficiency' of the process,
II. defining all the major elements of process as elements which impact the efficiency of the system,

III. defining relationships between the elements of the system as relationships which impact the efficiency of the system,

IV. setting the congruence/incongruence of the elements which impacts the efficiency of the transformation.

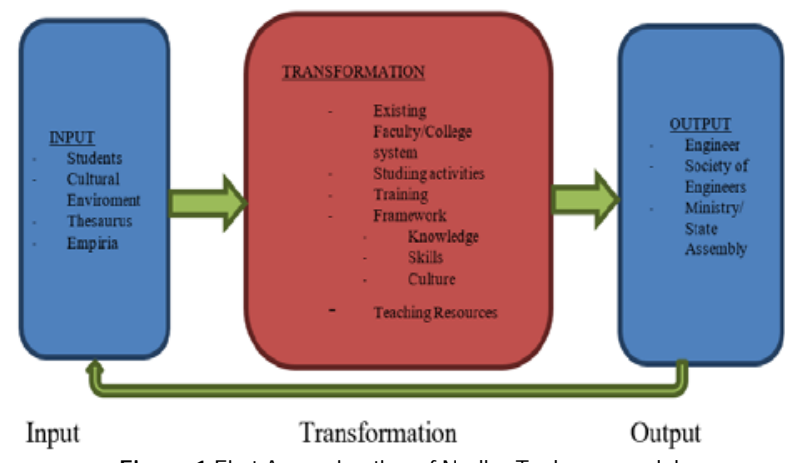

Figure 1 First Approximation of Nadler Tushman model

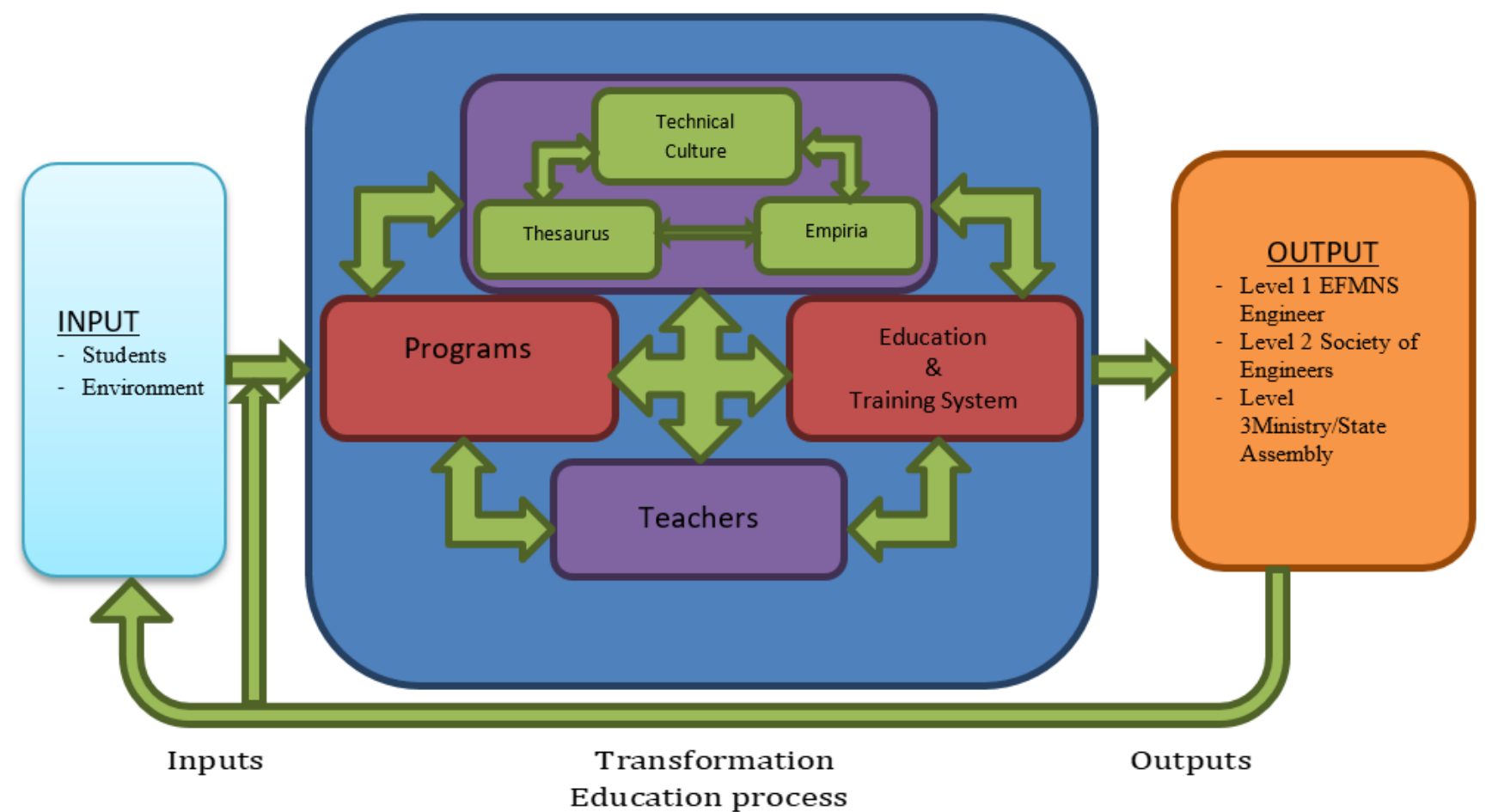

Figure 2 Modified Nadler Tushman model SF13 of Education process

Where:

- Culture

- Work benchmarks Programs

- $\quad$ Structure benchmarks Education and Training System (Universities/Faculties/Schools)

\section{- People benchmarks Teachers (Teachers/Expert} Consultants/Training masters)

or if we step back to the basics/origins of Nadler-Tushman model:

- Individuals benchmarks Teachers / Students
- Tasks benchmarks Programs

- Formal process benchmarks Eduction\&Training System (ETS)

- Informal process benchmarks synergie of Technical culture/Thesaurus/Empiria (TTE).

According to the authors research and [20] analysis of the new SF13 model has to be conducted in step-by-step analysis in three steps. 


\section{STEP-BY-STEP ANALYSIS}

\subsection{Step One: Analysis of Each Element}

\section{Programs}

There are a lot of Programs which handle maintenance, all of which are different in contents and duration.

Critical task of every program is to provide/obtain knowledge for students through enough courses for engineer degree and EFMNS certificate.

Performance support:

First perspective: What has education done? Enough for engineering degree and EFMNS certificate

Second perspective: How is education processed? Through several areas of education and several types of courses.

\section{Technical culture/Thesaurus/Empiria (TTE)}

Technical culture is probably the element which is one of the greatest influences. Values of Technical culture are values of ongoing development of society. Values of technical culture have changed in history as well as the relationships and dependencies between technical culture and the structures in which a person lives and works [21].

It is necessary to define the concept of the technical culture and to show its teaching essence. On the other hand, we have to indicate the range of values in the culture of technology, determining the value of the technological culture and values, which are developed by the technical culture.

Finally, indication of the interaction between the technical culture and values is the measurement of influence on the society.

Thesaurus as "treasure of knowledge" is also a significant factor.

Empiria as a storage of experience has a great influence in this part of educational process.

\section{Teachers}

Teachers/Expert Consultants/Training masters are the main medium in transformation process. Transferring and directing, they are with programs key indicators of transformation process.

\section{Education and Training System (ETS)}

Education system which is represented by University/Faculty/School states the system of acquiring levels of knowledge through sets of rules and indicators. As achieved practical knowledge is necessary for EFMNS certificate training is also important.

\subsection{Step Two: Analysis of Relationship Between the Elements}

In order to determine relationship between the recognized elements of educational process system and their synergy/congruence or incongruence basic mutual impact has to be established.

Also, the field of research has to be narrowed to Serbia, although it could be applied to Europe, concrete scoring has to be done for each environment, as it differs from country to country.

Through this research and analysis only the level one output is considered in order to conduct gap analysis of particular form of individual education.
Elements of NadlerTushman SF13 model are:

$E_{N T S F 13}=\{P, T, T T E, E T S\}$

and incongruence can be presented as:

$\operatorname{Inc}\left(E_{N T S F 13}\right)=F\left(\operatorname{Inc}\left(E_{N T S F 13}, E_{N T S F 13}^{\mathrm{T}}\right)\right)$

Incongruence of particular element to each other is:

$\operatorname{Inc}\left(P_{T}\right)=F(\operatorname{Inc}(P, T))$

$\operatorname{Inc}\left(T_{P}\right)=F(\operatorname{Inc}(\mathrm{ETS}, \mathrm{P}))$

$\operatorname{Inc}\left(\operatorname{ETS}_{P}\right)=F(\operatorname{Inc}(\mathrm{ETS}, \mathrm{P}))$

Main relationship of elements lies in two relations which are: "basis of" and "depends on"; each representing the main and most important "congruence" relation between elements, describing their connections in a logical sense, and we can describe it as:

$$
\begin{aligned}
& \operatorname{IncB}\left(E_{\text {NTSF } 13}\right)=B\left(\left(E_{N T S F 13}, E_{N T S F 13}^{\mathrm{T}}\right)\right) \\
& \operatorname{IncDeps}\left(E_{N T S F 13}\right)=\operatorname{Deps}\left(\left(E_{N T S F 13}, E_{N T S F 13}^{\mathrm{T}}\right)\right)
\end{aligned}
$$

The third, but not the last element in the matter of scope of an analysis, is "develops" relation, used in order to make the system live and developing through time line of the educational process itself and scientific and expert development, presented as:

$$
\operatorname{IncDevs}\left(E_{N T S F 13}\right)=\operatorname{Devs}\left(\left(E_{N T S F 13}, E_{N T S F 13}^{\mathrm{T}}\right)\right)
$$

Since the modified Nadler Tushman model SF13 is established, one can choose different relations in order to conduct other analysis, giving us a large scope of results i.e. number and qualification of teachers, number of ESPB points required in educational and training system etc.

Gap between elements incongruence can be presented as:

$G\left(E_{N T S F 13}\right)=N-\operatorname{Inc}\left(E_{N T S F 13}\right)$

where $N$ - nominal incongruence

Analogously to previous, we can calculate the gap for each relationship.

$$
\begin{aligned}
& G_{B}\left(E_{N T S F 13}\right)=N_{B}-\operatorname{IncB}\left(E_{N T S F 13}\right) \\
& G_{\text {Devs }}\left(E_{N T S F 13}\right)=N_{\text {Devs }}-\operatorname{IncDevs}\left(E_{N T S F 13}\right) \\
& G_{\text {Deps }}\left(E_{N T S F 13}\right)=N_{\text {Deps }}-\operatorname{IncDeps}\left(E_{N T S F 13}\right)
\end{aligned}
$$

For the purpose of gap analysis of the educational programs and required knowledge mentioned three relations will produce enough scoring to conduct analysis. 
According to [22] inquiry-based learning can be defined as a process of discovering new causal relations, with the learner formulating hypotheses and testing them by conducting experiments and/or making observations.

Analysis was done by Question \& Answer matrix using "basis of", "develops" and "depends on" relationship.

Scoreboard matrix of results is:

$$
\begin{aligned}
& \text { ScoreboardMatrix }_{\operatorname{Inc}\left(E_{N T S F 13}\right)}= \\
& N_{B} \operatorname{IncB}\left(E_{N T S F 13}\right) G_{B}\left(E_{N T S F 13}\right) \\
& N_{\text {Devs }} \operatorname{IncDevs}\left(E_{N T S F 13}\right) G_{\text {Devs }}\left(E_{N T S F 13}\right) \\
& N_{\text {Deps }} \operatorname{IncDeps}\left(E_{N T S F 13}\right) G_{\text {Deps }}\left(E_{N T S F 13}\right)
\end{aligned}
$$

Incongruence factor scoring is used to find valued scores of interactions. Incongruence factor scale: from 1 to 3 where 3 is the strongest i.e. $\operatorname{Inc}\left(E_{N T S F} 13\right)=(1,2,3)$
Desired system output on level one: student with master engineering degree and EFMNS certificate ability, therefore all incongruences of the system elements are based on the level one of the outputs of the system.

\subsection{Step Three: Building and Sustaining the Congruence}

Sustainable congruence is congruence of relationship between elements of the system.

Building congruence in the modified Nadler-Tushman model SF13 is considering steps we could take to reconfigure each element, and resolve relationship between the incongruence factor parameters we have identified.

Therefore, we shall establish Score Board table of incongruence factors which we will analyse to get incongruences. i.e. gaps.

Table 1 Score Board Matrix of Incongruence of Educational process (Eq. (11))

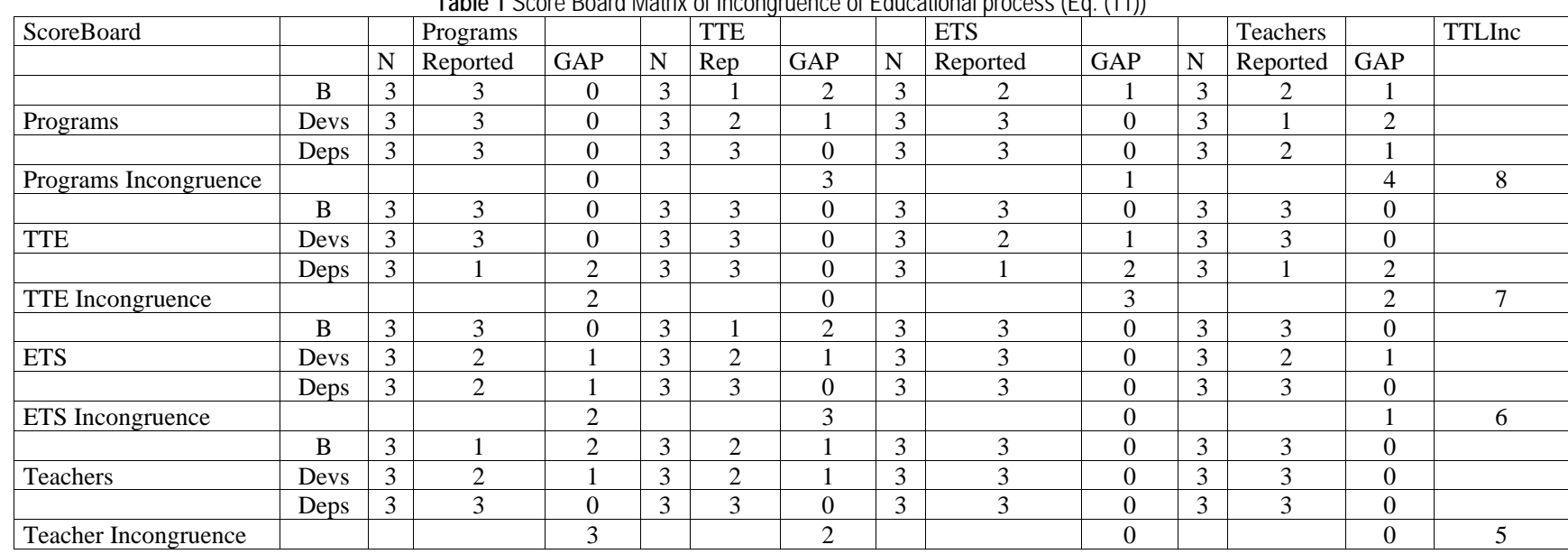

Score Board table shows incongruence of the used modified Nadler Tushman model SF13 elements of Educational process of EFMNS engineer, where:

- $\quad$ N-nominal Inc equals maximum $\operatorname{Inc}\left(E_{N T S F} 13\right)=(3)$

- $\quad$ Reported-reported Inc $\left(E_{N T S F} 13\right)$

- TTL Inc-total incongruence of elements

As shown incongruence of elements identifies Programs as most incongruent element of the Education process as a system then TTE, ETS and Teachers.

Also we find that Programs have the most impact on the output level one of the system.

Therefore, the system identifies further GAP analysis of Programs element as solution for achieving better performance of the educational process.

More profound analysis gives that GAP analysis of Programs must be conducted considering mutual incongruent factor analysis of elements influencing Programs and vice versa.

Improvement of other elements of the system should not be forgotten hence their mutual incongruence could be changed over the time once they had been changed.

Note that presented model can be used in other processes like engineering, maintenance and management that can be approximated with system with inputs/outputs consisting of elements and their relationships known to the user of the system. Also it can handle inner interactions of sub elements of the system while subelements belong to the same group of subelements forming one element of the system.

\section{ANALYSIS OF MATRIX OF EDUCATIONAL PROGRAMS AND RESULTS}

Researching the educational programs which deal with maintenance area, author of this paper focused on and analysed the programs of four major mechanical faculties in Serbia: Mechanical faculty in Belgrade [23, 24], Faculty of technical sciences in Novi Sad (mechanical department) [25], Mechanical faculty in Kragujevac [26] and Mechanical faculty in Niš $[27,28]$.

All programs, both Bachelor and Master degree, can be illustrated in one general matrix of subjects, generally divided in three or four area of education courses (academical general education, theoreticalmethodological, scientific-expert and expert applicable), staggered in semester/year of study.

This matrix gives good platform for gap analysis since all of them have mandatory and electoral subjects/topics.

Further analysis of programs results in the fact that mandatory courses, especially in academic general and theoretical-methodical areas are generally the same in all programs and do not affect the educational system as they represent basic knowledge required as entry level stage of courses required by EFMNS. 
Furthermore, comparing for example [11] with [23, 24] and related electoral course given in present educational system we find several courses which deal with some of the [11] topics, like Business-production informational systems, Business management, Informational integration of business function, Reparation of mechanical parts and construction etc. but none of the mentioned or listed in $[23,24]$ has a set of topics at the level of taxology required and deal with maintenance itself. Similar situation is in other referenced programs which indicates that the gap has to be fulfilled by introducing new electoral course.

Over all, electoral courses in Programs do not make significant incongruence to Educational \& training System and approach to build electoral courses with required knowledge, which can be added to similar programs, leave as freedom of changing one element of the system without making strong interference to other elements of the system so further post analysis can be done.

If we narrow the research to Mechanical faculty in Belgrade, then considering mandatory courses and their programs we have thirteen electoral courses in one semester duration to fulfil the gap of missing topics.

Analysis of all programs expressed in two generic matrix and EFMNS required knowledge [11] results in two matrix of educational program, both Bachelor and Masters programs, that has to fulfil desired outputs of the educational process system.

Using conclusions from [13], practice has to be more present and it is not counted in electoral courses. Also, according to $[1,2]$ and related, expert knowledge in maintenance methods and techniques has to be established as a necessary content of educational courses.

According to [7, 11, 13, 23, 24, 15] electoral courses have to be divided in two categories: basic academic studies and master academic studies according to the entry level knowledge of student. Respecting levels of academic knowledge there is a list of courses to be added in BAS and MAS.

\section{Bachelor Academic Study (BAS) list of electoral} courses

1. Electoral course 1 Basics of maintenance

2. Electoral course 2 Maintenance management 1 [11] ch. 3.1. p. 1-3

3. Electoral course 3 Organization of maintenance 1 [11] ch. 3.1. p. 7-9, 11

4. Electoral course 4 Maintenance informational systems [11] ch. 3.3. p. 1-6

5. Electoral course 5 Maintenance methods and Techniques 1 [11] ch. 3.4. p. 1-4, 11

6. Electoral course 6 English language (maintenance)

\section{Master Academic Study (MAS) list of electoral} courses

1. Electoral course 7 Organization of maintenance 2 [11] ch. 3.1. p. 12-18; ch. 3.2. p. 7, 8, 11

2. Electoral course 8 Maintenance methods and Techniques 2 [11] ch. 3.4. p. 5-10

3. Electoral course 9 Maintenance methods and Techniques 3 (TQM, RBI, TPM, RCM, CBM, TBM, FMEA, FMECA...)
4. Electoral course 10 Maintenance management 2 [11] ch. 3.1. p. 3-6, 10

5. Electoral course 11 Reliability [11] ch. 3.2. p. 1, 6, 9, 10

6. Electoral course 12 Maintainability [11] ch. 3.2. p. 25

7. Electoral course 13 Asset care, failure, strategy [7] pg. 50-51

Presented list covers minimum requirements of EFMNS with given chapters and points as program of the course itself.

\section{POSTMODULATION ANALYSIS OF THE SYSTEM}

After eliminating gap in the program as one of the elements with greatest impact factor on the educational process by implementing all minimum requirements of the knowledge we can analyse the system again.

New scoreboard can be designed in order to find new interactions of the elements and their impact to the system.

New scoreboard matrix shows new incongruence in the system and that element Teachers have most incongruence with the score of 9. The result is expected and logical.

Also, if we consider teacher student [29] as one relationship we can deal with, then we have to consider teacher professional development and improvement.

Especially, according to [30] in post analysis we have to take special care of teacher leadership, which shows that leadership is second among all school-related factors that contribute to what students learn at school, which leads us to conclusion that EFMNS certified engineers, as teaching leaders, must be engaged in educational process.

After filling the gap in Teachers element and shrinking incongruence, new analysis can be redone. And so on.

Using this kind of iteration, we can modify the system in enough steps we need, starting from most influential element, or more incongruent element. If the matter of our analysis asks, we can do it from the point of view of our aim.

The system as it is modified can be used to analyse every element by itself or as a whole.

Future researchers can use freely this modified Nadler Tushman model for their analysis of educational process.

\section{FINAL ANALYSIS AND CONCLUSIONS}

Benchmarking of different processes, as system models, and finding analogy in comparing system elements and their relationships, indicates GAP analysis as a most efficient way to conduct various analysis of the process itself.

Modified Nadler-Tushman model SF13 as one of gap analysis methods, combining theory of system and relationships of the elements in the transformation (system itself) provides us easy and rational way to conduct analysis of one process.

Modified Nadler Tushman model SF13 has ability to deal in several dimensions; as gap of element and as gap of system (system output incongruence). Also it can provide analysis of different levels (layers) of output and their incongruence. All of it through time. 
Comparing the results of this analysis and the model developed for the purpose of finding the solution for educating EFMNS capable engineer with some researches in the similar area i.e. educating engineers in some specific field of sustainability development [14] where rebuilding of complete curriculum is proposed, within topic of maintenance, which is widely spread in educational process of mechanical engineer, it is not necessary to rebuild complete curriculum but only add missing (gap) topics through courses. However, both researches reveal that educating process of engineer capable of some area of specialty needs to be done in co-evolutionary process with the rest of society i.e. environment, levels of output etc.

On the other hand, if Modified Nadler Tushman model SF13 and its related scoreboard matrix can be compared with system typed models like i.e. [3] which deals with relatively weighted defined impact factors and clusters and hybrid approach using two models, we find similarity in deductive approach and use of theory of systems to define desired model but also we can find significantly different approach in dealing with elements of the system and their nature and environment such as culture-TTE, etc, and gap of element and gap of system analysis through level (layers) of output. Either model serves best for their purpose.

Simplicity and flexibility of Modified Nadler Tushman model SF13 although it can deal with three dimensional models representing researched system in three levels (layers) should provide its widely spread usage as research shows [16] that all fields of educational degree like to deal with simple evaluating methods.

Generally, there are two types of conclusions that can be made through this research:

1. First Type: Conclusions made on modified Nadler Tushman model SF13 itself,

2. Second Type: Conclusions made on using modified Nadler Tushman model SF13 on analysis of educational process of engineer capable of EFNMS certification.

\section{First Type of Conclusions:}

1. Using modified Nadler Tushman SF13 model one can benchmark various types of processes. i.e. education, production, design, technology etc. Modifying the Nadler Tushman model is possible only if requirements for benchmarking are fulfilled. Using modified Nadler Tushman SF13 model gives not only the congruence/incongruence of the system elements and their impact on the system but strong base for gap analysis of the elements themselves and levels (layers) of outputs.

2. Comparing education with business process one compares inputs and outputs with transformation in the system which provides most 'profit making' or most efficient way to transform input into output of the system. Basic principles of GAP analysis "where we are" and "where we want to be" were perfect in mapping of problem student-faculty-degree-knowledge in the area of maintenance management and EFMNS certification.

3. Presented model can be used in other processes like engineering, maintenance and management that can be approximated with system with inputs/outputs consisting of elements and their relationships known to the user of the system. Also it can handle inner interactions of sub elements of the system while sub elements belong to the same group of sub elements forming one element of the system. Analytics of the system can be done step by step with iteration $n-1$ steps (n-number of elements of a system, eliminating elements one-by one. Analytics of the system can be done through several levels of outputs changing layers of analytics using 3D matrix of scoreboards.

\section{Second Type of Conclusions:}

1. Modified Nadler Tushman, model SF13 as is modified can be used to analyse every element of the educational process itself or for analysis of incongruence of whole system. Eliminating gaps in Programs element of the system, other elements of system become more influenceive or more incongruent to the system with scoreboard matrix changing values. As stated TTE and the teachers have more impact to the system. TTE and E\&T Systems are more inertious and therefore have less impact to the system but their impact is long term. Further analysis can be done on the second level (engineer organizations and societies) and third level (society, country...) of outputs of the modified Nadler Tushman model.

2. Future research and analysis of educational process can be done through this modified Nadler Tushman model SF13, by choosing different relations between elements and making new scoreboard which will give us a large scope of results i.e. number and qualification of teachers, number of ESPB points required in educational and training system etc.

3. Expert knowledge in maintenance methods and techniques has to be established as necessary content of educational courses. Teachers-Programs interaction reveals that EFMNS experts have to be engaged in educational process. Economics, organization and management knowledge and skills have to be more present in both bachelor and master study program. Practise in real business environment has to be included in Education and training system.

4. Program designed to fill the gap of EFMNS relevant program with electoral courses can be separated as standalone education program with master degree in maintenance.

Finally, gap analysis of Programs, including this analysis conclusions and incongruence factor analysis, provided enough information for making model of education program to guide students and faculties/universities in choosing required expertise knowledge in the field of maintenance management for EFMNS certification.

\section{REFERENCES}

[1] Popović, V., Vasić, B., \& Petrović, M. (2010). The possibility for FMEA method improvement and its implementation into bus life cycle. Strojniški VestnikJournal of Mechanical Engineering, 56(3), 179-185 (UDC 658.56:629.34)

[2] Vujanović, D., Momčilović, V., \& Medar, O. (2018). Influence of an integrated maintenance management on the vehicle fleet energy efficiency. Thermal Science, 22(3), 1525-1536. https://doi.org/10.2298/TSCI170209122V

[3] Vujanović, D., Momčilović, V., \& Vasić, M. (2018). A hybrid multi-criteria decision making model for the vehicle service center selection with the aim to increase the vehicle 
fleet energy efficiency. Thermal Science, 22(3), 1549-1561. https://doi.org/10.2298/TSCI170530208V

[4] Bebic, D., Stazic, L., \& Komar, I. (2019). Ships Shore Service Optimization Using the Queueing Theory. International Journal of Simulation Modelling, 18(4), 596607. https://doi.org/10.2507/IJSIMM18(4)488

[5] Petrovic, S., Milosavljevic, P., \& Sajic, J.L. (2018). Rapid Evaluation of Maintenance Process Using Statistical Process Control and Simulation. International Journal of Simulation Modelling. 17(1), 119-132. https://doi.org/10.2507/IJSIMM17(1)424

[6] European Federation of National Maintenance Societies (http://www.efnms.eu/)

[7] Wilson, A., de Bruin, A., \& Eweg, E. (2008). Guide to Maintenance Management, Hogeschool Utrecht, University of Aplied Sciences, ISBN 978-90-813466-1-0

[8] European Federation of National Maintenance Societies, European Certification Committee

(http://www.efnms.eu/committees/european-certificationcommittee/)

[9] EN 15628:2014, CEN, Maintenance - Qualification of maintenance personnel,

[10] Filipović, S., Stanojević, N., \& Todorović, M. (2017). Review of maintenance standards related to reliability, safety and quality as well, Maintenance forum 2017, Budva. Pages 220-235, ISBN 978-86-84231-42-2

[11] European Federation of National Maintenance Societies, Requirements for EFMNS Certification (http://www.efnms.eu/wpcontent/uploads/2016/08/M_Req. pdf)

[12] European Federation of National Maintenance Societies, Expert list (http://www.efnms.eu/expert-list-maintenancemanagement/)

[13] Filipović, S. (2017). Strateški pristup upravljanju održavanjem tehničkih sistema kroz sistematsko obrazovanje i permanentno usavršavanje rukovodioca održavanja/Strategic aproach to maintenance management of technical systems through systematic education and permanent upgrade of maintenance managers, master's thesis, Mechanical faculty Belgrade

[14] Mulder, K., Segalas-Coral, J., \& Ferrer-Balas, D. (2010). Educating engineers for/in sustainable development? What we knew, what we learned, and what we should learn. Thermal Science, 14(3), 625-639. https://doi.org/10.2298/TSCl1003625M

[15] Joint Declaration of the European Ministers of Education convened in Bologna on 19 June 1999 (https://www.eurashe.eu/library/bologna_1999_bolognadeclaration-pdf/)

[16] Pšunder, I. \& Ferlan, N. (2007). Analysis of the Knowledge and the Use of Investment Project Evaluation Methods in the Field of Mechanical Engineering. Strojniški Vestnik Journal of Mechanical Engineering, 53(2007)9, 569581(UDC 330.322:621).

[17] Petropoulos, F., Kourentzes, N., Nikolopoulos, K., \& Siemsen, E. (2018). Judgmental selection of forecasting models. Journal of Operations Management, 60(2018), 3446. https://doi.org/10.1016/j.jom.2018.05.005

[18] Rouse, M. (2014). GAP analysis (https://searchcio.techtarget.com/definition/gap-analysis)

[19] Basu, C. (2018). Pros and Cons of the Congruence Model (https://smallbusiness.chron.com/pros-cons-congruencemodel-36161.html)

[20] Makentelow, J., Jackson, K., Swift, C., Edwards, S., Bishop, L., Mugridge, T., Bell, S., Robinson, R., \& Bruce, E. (2017). The Nadler Tushman Congruence model - Aligning the drivers for high performance

https://www.mindtools.com/pages/article/newSTR_95.htm
[21] Chałas, K. (2014). Technical culture and human axjosphere. Advances in Science and Technology Research Journal, 8(24), 107-110. https://doi.org/10.12913/22998624/577

[22] Pedaste, M., Mäeots, M., Siiman, L., de Jong, T., van Riesen, S., Kamp, E., Manoli, C., Zacharia, Z., \& Tsourlidaki, E. (2015). Phases of inquiry-based learning: Definitions and the inquiry cycle. Educational Research Review,14, 47-61. https://doi.org/10.1016/j.edurev.2015.02.003

[23] Faculty of Mechanical Engineering, Belgrade, Serbia, Bachelor Academic Study Program (https://www.mas.bg.ac.rs/studije/oas/start)

[24] Faculty of Mechanical Engineering, Belgrade, Serbia, Master Academic Study Program (https://www.mas.bg.ac.rs/studije/mas/start)

[25] Faculty of Technical Sciences , Novi Sad Serbia, Study Programs (http://www.ftn.uns.ac.rs/688425262/studijskiprogrami)

[26] Faculty of Mechanical Engineering Kragujevac, Serbia, Study Programs

(http://www.mfkg.rs/index.php?option=com_content\&view =article\&id=237\&Itemid=356)

[27] Faculty of Mechanical Engineering Niš, Serbia Study programs (https://www.masfak.ni.ac.rs/index.php/sr/201503-03-09-42-14/2015-03-03-09-58-58/shins-inz-nj-rs-v)

[28] Faculty of Mechanical Engineering Niš, Serbia Study programs (https://www.masfak.ni.ac.rs/index.php/sr/201503-03-09-42-14/2015-03-03-10-00-00/shins-ns-ru-ci-r-zv-iinz-nj-ring)

[29] Pennings, H., Brekelmans, M., Sadler, P, Claessens, L, van der Want, Tartwijk, A. (2018). Interpersonal adaptation in teacher-student interaction. Learning and Instruction 55 41e57. https://doi.org/10.1016/j.learninstruc.2017.09.005

[30] Wenner, J. \& Campbell, T. (2017). The Theoretical and Empirical Basis of Teacher Leadership: A Review of the Literature, Review of Educational.

\section{Contact information}

Srđan FILIPOVIĆ, mr

(Corresponding author)

PUC "Public Services",

Porečka 28a, 12000 Požarevac, Serbia

E-mail: srdjan.v.filipovic@gmail.com

\section{Miloš VASIĆ, MSc}

University of Belgrade

Faculty of Mechanical Engineering,

Kraljice Marije 16, 11000 Belgrade, Serbia

E-mail: milos.vasic@mas.bg.ac.rs

Slaven TICA, prof. dr

University of Belgrade,

Faculty of Transport and Traffic Engineering,

Vojvode Stepe 305, 11000 Belgrade, Serbia

E-mail: slaven.tica@sf.bg.ac.rs

Emil VEG, prof. dr

University of Belgrade

Faculty of Mechanical Engineering,

Kraljice Marije 16, 11000 Belgrade, Serbia

E-mail: emil.veg@mas.bg.ac.rs

Goran ŠINIKOVIć, prof. d

University of Belgrade,

Faculty of Mechanical Engineering,

Kraljice Marije 16, 11000 Belgrade, Serbia

E-mail: gsinikovic@mas.bg.ac.rs 